\title{
Effect of centrifugal force on the development of articular neocartilage with bovine primary chondrocytes
}

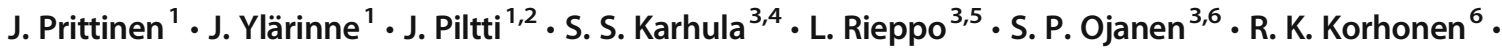 \\ S. Saarakkala ${ }^{3,5,7} \cdot$ M. J. Lammi ${ }^{1,8} \cdot$ C. $\mathrm{Qu}^{1}$
}

Received: 27 March 2018 / Accepted: 4 October 2018 / Published online: 23 October 2018

(C) The Author(s) 2018

\begin{abstract}
A lot has been invested into understanding how to assemble cartilage tissue in vitro and various designs have been developed to manufacture cartilage tissue with native-like biological properties. So far, no satisfactory design has been presented. Bovine primary chondrocytes are used to self-assemble scaffold-free constructs to investigate whether mechanical loading by centrifugal force would be useful in manufacturing cartilage tissue in vitro. Six million chondrocytes were laid on top of defatted bone disks placed inside an agarose well in 50-ml culture tubes. The constructs were centrifuged once or three times per day for $15 \mathrm{~min}$ at a centrifugal force of $771 \times g$ for up to 4 weeks. Control samples were cultured under the same conditions without exposure to centrifugation. The samples were analysed by (immuno)histochemistry, Fourier transform infrared imaging, micro-computed tomography, biochemical and gene expression analyses. Biomechanical testing was also performed. The centrifuged tissues had a more even surface covering a larger area of the bone disk. Fourier transform infrared imaging analysis indicated a higher concentration of collagen in the top and bottom edges in some of the centrifuged samples. Glycosaminoglycan contents increased along the culture, while collagen content remained at a rather constant level. Aggrecan and procollagen $\alpha_{1}$ (II) gene expression levels had no significant differences, while procollagen $\alpha_{2}(\mathrm{I})$ levels were increased significantly. Biomechanical analyses did not reveal remarkable changes. The centrifugation regimes lead to more uniform tissue constructs, whereas improved biological properties of the native tissue could not be obtained by centrifugation.
\end{abstract}

Keywords Centrifugal force $\cdot$ Cartilage tissue engineering $\cdot$ Primary chondrocyte $\cdot$ Tissue assembly $\cdot$ Osteoarthritis

J. Prittinen

juha.prittinen@umu.se

M. J. Lammi

mikko.lammi@umu.se

J. Ylärinne

janne.ylarinne@immunodiagnostic.fi

J. Piltti

juha.piltti@umu.se

S. S. Karhula

sakari.karhula@oulu.fi

L. Rieppo

lassi.rieppo@oulu.fi

S. P. Ojanen

simo.ojanen@uef.fi

R. K. Korhonen

rami.korhonen@uef.fi

S. Saarakkala

simo.saarakkala@oulu.fi
C. $\mathrm{Qu}$

chengjuan.qu@umu.se

1 Department of Integrative Medical Biology, Umeå University, Umeå, Sweden

2 Nordlab Kokkola, Keski-Pohjanmaa Central Hospital Soite, 40620 Kokkola, Finland

3 Research Unit of Medical Imaging, Physics and Technology, Faculty of Medicine, University of Oulu, Oulu, Finland

4 Infotech Doctoral Program, University of Oulu, Oulu, Finland

5 Medical Research Center Oulu, Oulu University Hospital and University of Oulu, Oulu, Finland

6 Department of Applied Physics, University of Eastern Finland, Kuopio, Finland

7 Department of Diagnostic Radiology, Oulu University Hospital, Oulu, Finland

8 School of Public Health, Health Science Center, Key Laboratory of Trace Elements and Endemic Diseases, National Health and Family Planning Commission, Xi' an Jiaotong University, Xi'an, China 


\section{Introduction}

Articular cartilage has a limited ability for self-repair and, when damaged, it has a high risk of progressing into osteoarthritis, if not intervened. Current strategies to treat full-depth cartilage defects are microfracture (Mithoefer et al. 2009), autologous chondrocyte implantation (Harris et al. 2010; Peterson et al. 2010) and osteochondral grafts (Lynch et al. 2015). There are still several drawbacks with all of these methods, which have led to attempts to develop various tissue engineering techniques to create in vitro grown implants in hopes of combining the advantages of autologous chondrocyte implantation and mosaicplasty. One such approach is to manufacture constructs with the mechanical and biological properties of the native articular cartilage (Moutos et al. 2007). Attempts have been made to deliver appropriate biomaterials with or without cells to facilitate cell growth and native regenerative processes, which may involve interactions among the cells and biomolecules, such as growth factors. However, there has been a limited success in consistently producing native-like articular cartilage in vitro (Yang et al. 2017). Advances in the development of cell-laden hydrogels still offer new possibilities to improve the physical and biological properties of the next-generation matrices applicable for osteochondral/cartilage tissue engineering. On the other hand, scaffold-free approaches can mimic elements of native developmental processes (DuRaine et al. 2015).

Traditional scaffolds used for articular cartilage tissue engineering, manufactured out of synthetic hydrogels or biological matrices, have been good at providing mechanical support but have been poor at creating the correct assembly of the native cartilage (Trzeciak et al. 2016; Yang et al. 2017). More recently, efforts have been carried out to create chemically or mechanically distinct layers into the scaffold to mimic the different zones of the cartilage, and to provide the chondrocytes with realistic niches (Tatman et al. 2015). Even though these methods often manage to reproduce some desired characteristics of the articular cartilage, they failed to reproduce the whole range of the structural and mechanical properties of the native cartilage.

Scaffold-free methods get their rationale from mimicking embryonic and postnatal cartilage development. The main difference of the scaffold-free method from the native cartilage development is a lack of tissue turnover as it develops. The native cartilage develops its typical anisotropic organisation as the cartilage grows rather than through tissue remodelling. This has the benefit of having stem cells in the superficial zone that provide new chondrocytes to the tissue assembling an extracellular matrix (ECM) structure as the chondrocytes are caught up by the lower radial zone and begin to hypertrophy (Hunziker et al. 2007). In scaffold-free tissue engineering, adult chondrocytes are expected to mirror these developmental steps in ECM production and maturation. The self-assembly method has been shown to induce improved ECM production, although it still falls short of the native cartilage (Ofek et al. 2008). Mechanical stimulation has been shown to improve the mechanical properties of the tissue constructs (Hung et al. 2004) and several stress regimes and systems have been developed to find the best way to produce neocartilage that would be mechanically comparable to the native cartilage (Natenstedt et al. 2015).

Mechanical force is known to regulate the ECM production in connective tissues (Chiquet et al. 2003; Meinert et al. 2017a; Meinert et al. 2017b; Sarasa-Renedo and Chiquet 2005). The mechanical loading of the chondrocytes has been shown to increase tissue glycosaminoglycan (GAG) and type II collagen contents (Natenstedt et al. 2015; Parkkinen et al. 1993; Parkkinen et al. 1992). In human chondrocytes, it has been further demonstrated that uni- and biaxial mechanical loading enhanced the biochemical properties of neocartilage and the hyaline cartilage-specific gene expression in hydrogels composed of gelatin methacryloyl and hyaluronic acid methacrylate (Meinert et al. 2017a). Compressive loading improved the mechanical properties of artificial cartilage in a study with agarose gel as an artificial cartilage implant (Wang et al. 2018). Compression of the cartilage affected the size of the chondrocytes and the cell organelles, which is one possible way of mechanotransduction (Szafranski et al. 2004). The mechanical stimulation of chondrocytes has also been shown to activate ion channels and integrin-mediated signalling (Ramage et al. 2009). However, even though dynamic compressive loading of chondrocytes has been shown to have a positive effect on the expression of chondrogenic genes in the majority of studies, some controversial and negative effects have been shown as well (Anderson and Johnstone 2017). Various models, such as hydrostatic pressure (Cheleschi et al. 2017; De Palma et al. 2018; Parkkinen et al. 1993; Pascarelli et al. 2015) and centrifugation (Kim et al. 2017), have been used to investigate the influence of mechanical forces at the cellular level in normal and/or osteoarthritic human chondrocytes. Hydrostatic pressure (1-5 MPa, frequency $0.25 \mathrm{~Hz}$ for a period of $3 \mathrm{~h}$ ) upregulated some microRNAs but downregulated MMP-13, ADAMTS-5 and HDAC-4 via Wnt/ $\beta$-catenin or NF-kB pathway (Cheleschi et al. 2017; De Palma et al. 2018). Centrifugation is the most useful and simplest method, which does not need complicated devices and is not affected by the surrounding environment. Previously, it has been reported that centrifugation stimulated proteoglycan (PG) synthesis in articular and growth plate chondrocytes (Inoue et al. 1990).

Therefore, in this study, we examine the effect of centrifugal force on the development of neocartilage in a biphasic scaffold-free cell culture environment. We assume that the centrifugal force would increase the production of the cartilage ECM components and their correct organisation and, thus, improve the biomechanical properties of the neotissue construct. 


\section{Materials and methods}

\section{Chondrocyte cultivation}

The tissue culture vessels were created into 50-ml centrifugation tubes. An agarose (Agaros Standard, Saveen Werner, Sweden) gel well was cast in the bottom of each tube and a bovine femoral bone disk, defatted with several incubations with acetone and absolute ethanol, was placed into the middle of the well (Fig. 1a, b). A calcium phosphate layer was precipitated by three repeated treatments with $0.125 \mathrm{M} \mathrm{CaCl}_{2}$ and $0.5 \mathrm{M} \mathrm{NaH}_{2} \mathrm{PO}_{4}$ on one side of the bone disk, to partially block the pores and to form a substitute for subchondral bone. First, a bone disk was placed on top of a $25-\mu$ ldroplet of $\mathrm{CaCl}_{2}$, then an equal amount of $\mathrm{NaH}_{2} \mathrm{PO}_{4}$ was injected under the bone disk to improve precipitation on the bone. Next, two more treatments were performed after the water had evaporated. The bone disks were then placed into the agarose wells.

Tissues were grown using primary chondrocytes isolated from bovine knees (approximately 18 months of age), which were acquired from a nearby abattoir (Nyhléns Hugosons, Luleå, Sweden). The cartilage layer was cut out from femoral condyles of the knees and the chondrocytes were liberated with an overnight collagenase digestion (Clostridiopeptidase A, $100 \mathrm{U} / \mathrm{ml}$, Sigma-Aldrich) under stirring according to a previously tested program ( $10 \mathrm{~h}$ on, $2 \mathrm{~h}$ off, $1 \mathrm{~h}$ on, $2 \mathrm{~h}$ off, $1 \mathrm{~h}$ on, $2 \mathrm{~h}$ off, $1 \mathrm{~h}$ on and then off for the rest of the digestion). Digestion medium comprises serum-free high-glucose Dulbecco's Modified Eagle Medium Glutamax ${ }^{\mathrm{TM}}$ (Gibco/ Thermo Fisher Scientific, Waltham, MA, USA), supplemented with $1 \%$ fetal bovine serum (FBS), $100 \mu \mathrm{g} / \mathrm{ml}$ streptomycin, $100 \mathrm{U} / \mathrm{ml}$ penicillin, and $50 \mu \mathrm{g} / \mathrm{ml}$ 2-phospho-L-ascorbic acid trisodium salt. The following day, the cells were filtered through a filter cloth (pore diameter: $115 \mu \mathrm{m}$, Sefar AG, Heiden, Switzerland), counted and seeded on top of the bone disks at a density of $6 \times 10^{6}$ cells per disk to form a laminar construct consisting of layers of bone, precipitated calcium phosphate and chondrocytes (Fig. 1b). The culture medium was as described above but with 10\% FBS and without collagenase. Half of the culture medium was changed every second day during the culture period. Osteochondral type of neotissue was grown on top of bone discs during the 4-week culture periods (Fig. 1c-c'").

\section{Centrifugation regime}

After seeding, the cells were allowed to attach to the bone disk for $24 \mathrm{~h}$ before starting the centrifugation regime. The cells were subjected to centrifugal force $(771 \times g)$ for 15 min either once or three times per day with $3 \mathrm{~h}$ of rest between the centrifugations. The control samples were not centrifuged at all. The samples were collected after 1,2 and 4 weeks of culture by carefully removing the cartilage neotissues from the bone surface with a scalpel to collect samples for RNA, GAG and collagen analyses. For other analyses, the construct was left intact. The experiments were repeated at least three times with the cells from different donors.

\section{Gene expression}

Expressions of chondrocyte-specific genes and procollagen $\alpha_{2}$ (I) were performed with quantitative real-time RT-PCR (qRT-PCR). Total RNA was extracted using TRI Reagent according to the manufacturer's instructions. Reverse
Fig. 1 An agarose gel cast inside a 50-ml centrifugation tube contained a well for a bone disk (red). Calcium phosphate precipitate layer (yellow) was directed to the top and chondrocyte suspension (beige) was layered on top of the bone disk $(\mathrm{a}, \mathrm{b})$. After 4 weeks of culture, it was evident that the non-centrifuged tissues (c) were not as uniform as the two-time centrifuged $\left(c^{\prime}\right)$ or the three-time centrifuged $\left(\mathrm{c}^{\prime \prime}\right)$ tissues. Scale bar $=5 \mathrm{~mm}$
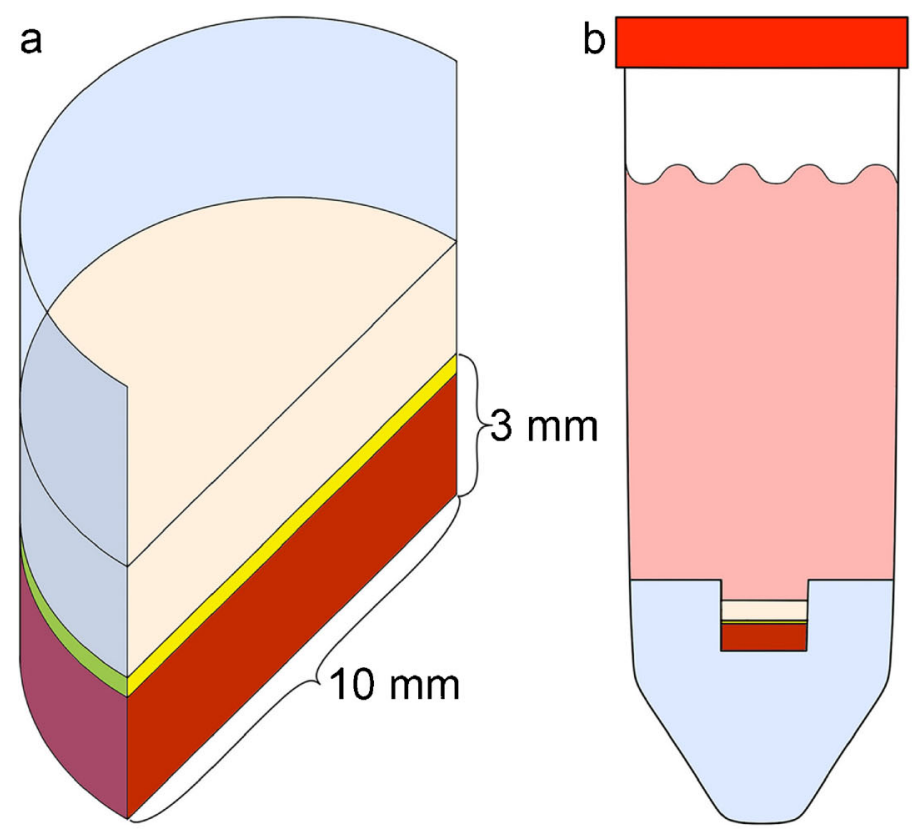
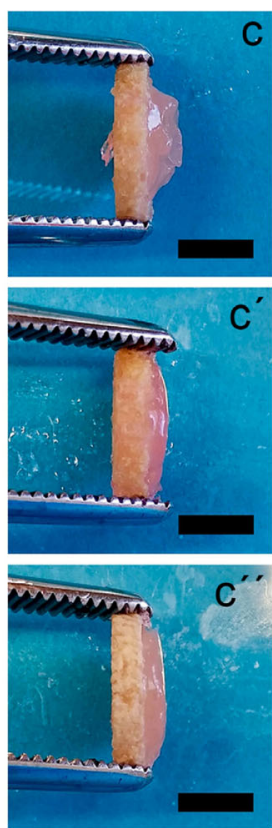
transcription was performed with iScript cDNA synthesis kit (Bio-Rad, Hercules, USA). qRT-PCR was performed using $\mathrm{iQ}^{\mathrm{TM}}$ SYBR ${ }^{\circledR}$ Green Supermix (Bio-Rad) and a CFX Connect ${ }^{\mathrm{TM}}$ system (Bio-Rad). Each reaction was performed in triplicate. Analyses were performed for the genes of interest listed in Table 1. All values were normalised to the housekeeping gene ribosomal protein, large, P0 (RPLP0).

\section{Biomechanical testing}

Biomechanical measurements of the neocartilage tissues at each time point $(n \geq 3)$ were conducted in indentation geometry using $250 \mathrm{~g}$ load cell and a flat-ended cylindrical indenter $(\varnothing=2 \mathrm{~mm}$ ) (Korhonen et al. 2002). Prior to biomechanical analysis, the tissue samples were stored at $-20{ }^{\circ} \mathrm{C}$ until all samples were collected. Samples were thawed at room temperature and the thicknesses of the neocartilage samples were measured using optical coherence tomography before biomechanical measurements (Puhakka et al. 2016).

The bone surface of the samples were glued with cyanoacrylate on the measurement chamber and submerged in phosphate-buffered saline (PBS). At the beginning of the biomechanical testing, the indenter was manually brought to contact with the sample surface and the tissue was preloaded and released 10 times by depressing $2 \%$ of the total thickness. The mechanical properties were measured adjacent to the centre of the sample with a four-step stress-relaxation protocol, where the tissue was compressed $5 \%$ of the remaining sample thickness at each step with a compression speed equal to the sample thickness per second. After every step, the tissue construct was allowed to relax for 15 min to ensure full relaxation of the tissue. A dynamic test with cyclic $1 \mathrm{~Hz}$ sinusoidal loading of four cycles was performed with an amplitude of $2 \%$ of the remaining thickness. Finally, equilibrium modulus was calculated from the stress-relaxation measurements and the dynamic modulus and phase angle from the sinusoidal test (Hayes et al. 1972; Mäkelä et al. 2014). Poisson's ratios were chosen to be 0.1 for the equilibrium modulus and 0.5 for the dynamic modulus analysis based on previous literature (Ateshian et al. 2007; Mow et al. 1980).

\section{Histology}

Manufactured tissues were fixed in $4 \%$ formalin for 5 days and then stored in $100 \%$ ethanol at room temperature. The tissues were then embedded in paraffin and cut into $5-\mu \mathrm{m}$ thick sections perpendicular to the surface from the middle of the tissue. The sections were stained for type II collagen using murine monoclonal antibody E8 (Holmdahl et al. 1986) and with toluidine blue to assess PG distribution. DAKO EnVision+ (Dako/Agilent, Santa Clara, USA) kit was used for immunostaining of the sections. The primary antibody was replaced by non-immune control serum in the negative control samples.

\section{Fourier transform infrared imaging microspectroscopy}

The collagen and GAG distributions were determined from the histological sections by using Fourier transform infrared imaging (FTIR) microspectroscopy to map their coverage in the constructs ranging from the centre to the lateral edge for the full cartilage thickness. Histological 5 - $\mu$ m-thick sections were placed on $\mathrm{ZnSe}$ windows for the measurements. Measurements were conducted with a Thermo iN10 FT-IR microscope (Thermo Nicolet Corporation, Madison, WI, USA) in transmission mode using spectral resolution of $8 \mathrm{~cm}^{-1}$ and a pixel size of $25 \times 25 \mu \mathrm{m}^{2}$. Eight repetitive acquisitions per pixel were averaged. The collagen and GAG contents were determined as the integrated areas of the amide I peak $\left(1584-1720 \mathrm{~cm}^{-1}\right)$ and the carbohydrate region (984 $1140 \mathrm{~cm}^{-1}$ ), respectively (Camacho et al. 2001; Rieppo et al. 2017). Collagen and GAG depth distribution was measured from a 500- $\mu \mathrm{m}$-wide section near the centre of the constructs and the thickness was scaled down to 100 points of measurement for comparison.

\section{Micro-computed tomography}

After fixing and storing the samples as described under histology, the tissues were treated with hexamethyldisilazane for three hours and left to dry overnight at room temperature.

Table 1 Bovine and human primers used for qRT-PCR analysis

\begin{tabular}{lll}
\hline Gene & Forward $\left(5^{\prime}-3^{\prime}\right)$ & Reverse $\left(5^{\prime}-3^{\prime}\right)$ \\
\hline Bovine RPLP0 (Donaldson et al. 2005) & CAACCCTGAAGTGCTTGACAT & AGGCAGATGGATCAGCCA \\
Bovine procollagen $\alpha_{1}(\mathrm{II})($ Galois et al. 2006) & CATCCCACCCTCTCACAGTT & GTCTCTGCCTTGACCCAAAG \\
Bovine procollagen $\alpha_{2}(\mathrm{I})($ Galois et al. 2006) & TGAGAGAGGGGTTGTTGGAC & AGGTTCACCCTTCACACCTG \\
Bovine aggrecan (Bosnakovski et al. 2006) & CACTGTTACCGCCACTTCCC & GACATCGTTCCACTCGCCCT \\
Bovine Sox9 (Tchetina et al. 2003) & CATGAAGATGACCGACGAG & GTTCTTGCTCGAGCCGTTGAC \\
Human RPLP0 (Donaldson et al. 2005) & AGATGCAGCAGATCCGCAT & GTGGTGATACCTAAAGCCTG \\
Human aggrecan (Donaldson et al. 2005) & AACATCATTCCACTCGCCCT & CACTGTTACCGCCACTTCCC \\
\hline
\end{tabular}


HMDS was used in order to dry the constructs, which would lead to better contrast. Subsequently, the samples were imaged using a micro-computed tomography (micro-CT) device (SkyScan 1272, Bruker microCT, Kontich, Belgium) with the following settings: $40 \mathrm{kV}$ tube voltage, $250 \mu \mathrm{A}$ tube current, 1800 projections, $1.0 \mu \mathrm{m}$ isotropic voxel side length, exposure of $1590 \mathrm{~ms} /$ frame, average of five frames per projection and without additional energy filtering. The scans were reconstructed with NRecon (v. 1.7.0.4, Bruker microCT) with beam hardening and ring artefact corrections applied.

Prior to porosity analysis, the partial volume effect was minimised by applying image filtering (unsharp mask filter followed by median filter) before segmenting cell volume from tissue volume with adaptive median- $\mathrm{C}$ thresholding. The ratios between chondron volume and tissue volume were calculated. Analysis, segmentation and image processing were then conducted with CTAnalyzer (v. 1.16.4.1, Bruker microCT).

\section{Glycosaminoglycan and collagen content analysis of the cartilage}

The wet mass of the neocartilage tissue was measured by weighing them after removing them from the culture system and wiping off the excess culture medium from the surface. The PGs were extracted for $24 \mathrm{~h}$ at $4{ }^{\circ} \mathrm{C}$ in $4 \mathrm{M}$ guanidine hydrochloride solution containing $50 \mathrm{mM}$ sodium acetate buffer ( $\mathrm{pH}$ 5.8), $5 \mathrm{mM}$ benzamidine hydrochloride and $10 \mathrm{mM}$ sodium EDTA (Qu et al. 2012; Ylärinne et al. 2014). The extracted PGs were precipitated in $75 \%$ ethanol and then dissolved in water. The GAG contents were assessed spectrophotometrically using dimethylmethylene blue assay (Farndale et al. 1986).

The extracted PGs were also separated using agarose gel electrophoresis as previously described (Qu et al. 2012) to identify the different sizes of PGs. Five micrograms of the extracted PGs was first dissolved in $10 \mu \mathrm{l}$ of SDS sample buffer mixed with $5 \mu$ l colour solution $(60 \%$ sucrose, $0.05 \%$, bromophenol blue in $1 \%$ TAE buffer, $w / v$ ) and then loaded to $1.2 \%$ agarose gel wells and run at a constant current of $50 \mathrm{~mA}$ and voltage of $35 \mathrm{~V}$ for approximately $3 \mathrm{~h}$. Finally, the gels were stained with toluidine blue followed by removal of excess stain with $3 \%$ acetic acid and photographed. The photograph was analysed with ImageJ to quantify the mobility of PGs. Zero percent mobility was defined as just after the wells and $100 \%$ mobility was defined as the point where chondroitin sulphate had lost most of its intensity. One hundred percent intensity was defined as the lowest pixel value in a grayscale photograph.

The collagen contents were estimated from the hydroxyproline contents in the tissue residues left after the PG extraction, digested overnight with papain $(1 \mathrm{mg} / \mathrm{ml}$ of enzyme in $5 \mathrm{mM}$ cysteine and $15 \mathrm{mM}$ EDTA in $150 \mathrm{mM}$ sodium acetate, $\mathrm{pH}$ 5.8, Sigma Aldrich). After the papain digestion, the samples were hydrolysed in $10 \mathrm{M} \mathrm{HCl}$ overnight at $108{ }^{\circ} \mathrm{C}$ and then neutralised with $\mathrm{NaOH}$. The hydroxyproline measurement was done with a spectrophotometric assay (Brown et al. 2001). Hydroxyproline concentrations were converted into collagen concentrations by multiplying the hydroxyproline content with a factor of 7.46 (Neuman and Logan 1950).

\section{Statistical analysis}

IBM SPSS statistics version 24 was used to perform MannWhitney $U$ test for detecting significant differences in gene expression, biomechanics and ECM composition between control and treated groups. The data are represented as means \pm standard deviation. $p$ values below 0.05 were considered statistically significant.

\section{Results}

\section{mRNA expression}

The effect of centrifugation and hydrostatic pressure on the maintenance of the chondrocyte phenotype was assessed with qRT-PCR analysis of chondrocyte-specific gene transcripts Sox9, aggrecan and procollagen $\alpha_{1}$ (II). Expression of procollagen $\alpha_{2}(\mathrm{I})$ was quantified in order to evaluate the possible loss of chondrocyte phenotype. The gene expressions of the transcription factor Sox9 were at a constant level at all exposures (Fig. 2a), while the expression of the major ECM component aggrecan had a tendency to increase with time, although there were no significant differences between any of the time points and experimental groups (Fig. 2b). Procollagen $\alpha_{1}$ (II) also did not display statistically significant changes at the various time points and treatments, despite the big increase in the mean values in three times centrifuged samples (Fig. 2c). The expression of procollagen $\alpha_{2}(\mathrm{I})$ increased significantly with time in all treatment groups, while it was significantly lower between control and three times centrifuged tissues at 1 week (Fig. 2d).

\section{Mechanical testing of the tissue constructs}

Functional effects of the centrifugation regimes were assessed through mechanical testing. The results revealed very few differences between the sample groups obviously due to high variations in some of the analyses. The equilibrium modulus appeared to increase with time in all groups, although the differences were not significant due to high variation (Fig. 3a). No statistical differences were evident in the dynamic moduli (Fig. $3 b)$. In general, the phase angle differences decreased with time, with a significant difference between control groups between 2 and 4-week cultivations (Fig. 3c). However, there were no significant differences between the control and centrifuged groups. 
Fig. 2 After each time point, RNA was extracted from half of a manufactured tissue construct and the expression of cartilage relevant genes Sox9 (a), aggrecan (b), procollagen $\alpha_{1}$ (II) (c) and procollagen $\alpha_{2}(\mathrm{I})$ (d) was measured. Expression levels are normalised to control at 1 week. Ctrl, non-centrifuged control; $1 \mathrm{C}$, one centrifugation per day; $3 \mathrm{C}$, three centrifugations per day. Statistically significant differences $(p<0.05)$ are marked with an asterisk (mean $+\mathrm{SD}, n \geq 3$ )
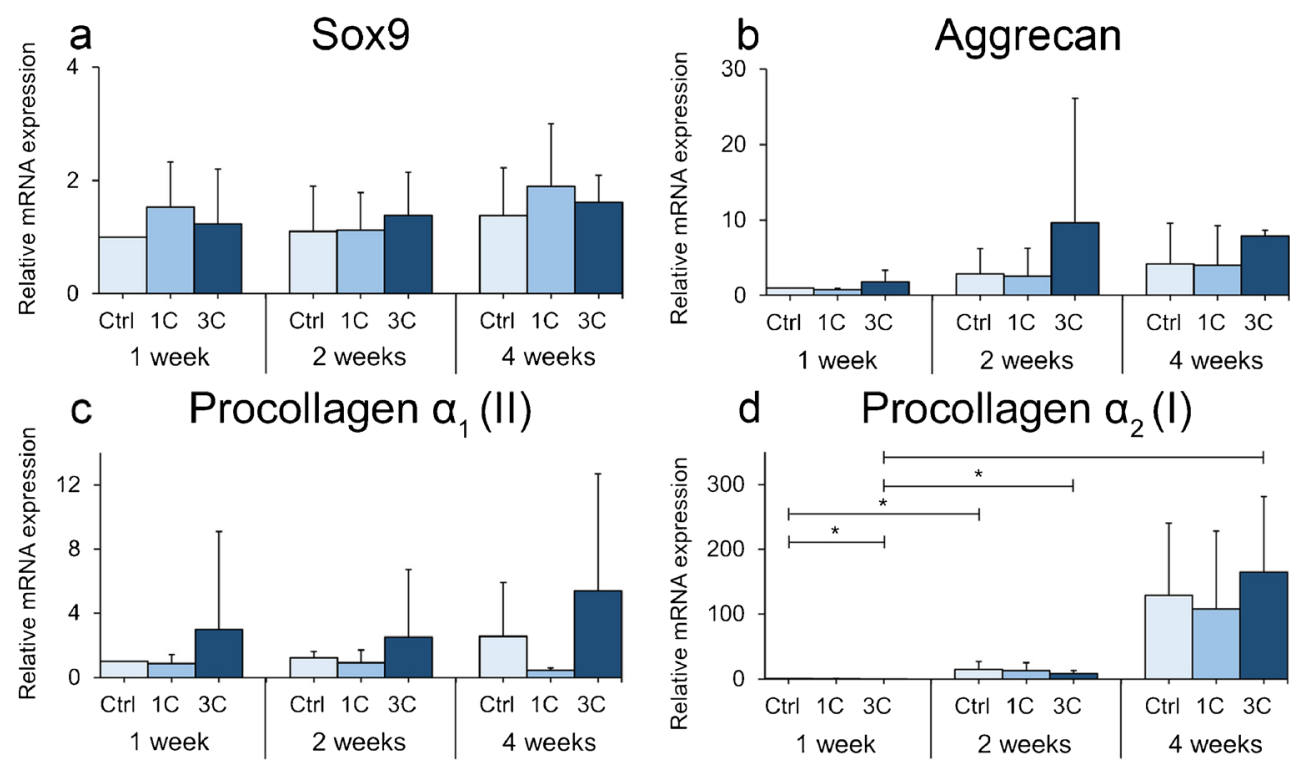

\section{Tissue morphology}

Tissue shape and morphology were studied from photographs and micro-CT images. The non-centrifuged tissues were generally thicker and less uniform in comparison to tissues from either centrifugation regime (Figs. 1c', $\left.\mathrm{c}^{\prime \prime}, 4\right)$. In general, the centrifuged tissues had a more even surface covering a larger area of the bone disk. Tissue porosity was evaluated from the micro-CT data obtained from the tissues cultured for 4 weeks. The porosities were $13.7 \% \pm$ $4.2 \%, 15.3 \% \pm 2.4 \%$ and $14.1 \% \pm 4.2 \%$ (mean and standard deviation, $n=5$ ) for control, once centrifuged and three times centrifuged groups, respectively. There were no statistically significant differences in the porosities between the treatments.

\section{Collagen and proteoglycan distribution}

Sections immunostained for type II collagen supported the FTIR results, although type II collagen appeared to be more evenly distributed throughout the tissue. Histological sections showed that type II collagen appeared to be relatively evenly spread throughout the tissue (Fig. 5b, b'). FTIR mapping of the amide I band, which is indicative of collagen content, revealed the highest collagen concentrations at the top and bottom edges in some of the once centrifuged tissues (Fig. $\left.5 \mathrm{e}^{\prime}\right)$. However, there was no clear difference in the collagen content profiles between the once centrifuged and control tissues (Fig. 5g, g'). The three-time-centrifuged tissues had a relatively even concentration of collagen in the surface and middle sections (Fig. 5g').

Toluidine blue staining of the histological sections in some of the one- and three-time-centrifuged tissues after 4 weeks of culture showed a zonal distribution of GAGs more similar to native cartilage (Fig. 5c', c'"), while some sections were stained hardly at all. The intensity of toluidine blue staining increased with longer culture time (data not shown). However, FTIR mapping of the carbohydrate region, which detects GAG content, revealed that GAGs were distributed more evenly throughout the tissues with no clear difference between the control and centrifuged samples (Fig. $5 \mathrm{f}-\mathrm{f}^{\prime \prime}$ ). Histological sections revealed that there were more areas void of ECM and cells inside the control samples when compared to sections from either centrifugation regime (data not shown). Close inspection of the surface revealed a flattened layer of cells (Fig. $\left.5 \mathrm{~d}-\mathrm{d}^{\prime \prime}\right)$.

\section{Biochemical analyses of collagen and proteoglycans}

Absolute collagen contents were estimated by analysing the hydroxyproline contents in the tissue samples. The values were rather uniform, so that the only significant difference was in control samples between 1- and 4-week-long cultivations (Fig. 6a). A trend for increased accumulation of GAGs along the culture time was noticed, which was statistically significant in controls after 2- and 4-week cultivations in comparison to 1 week (Fig. 6b). The PGs present in the tissues after a 4-week culture period consisted of large PGs (Fig. 6c), with similar sizes in each group, based on a densitometric analysis (Fig. 6d). The PGs of the native bovine cartilage had a slightly faster mobility, which indicates the metabolic clipping of the aggrecans.

\section{Discussion}

For tissue engineering efforts, the structural architecture of articular cartilage is the key element to reproduce native- 


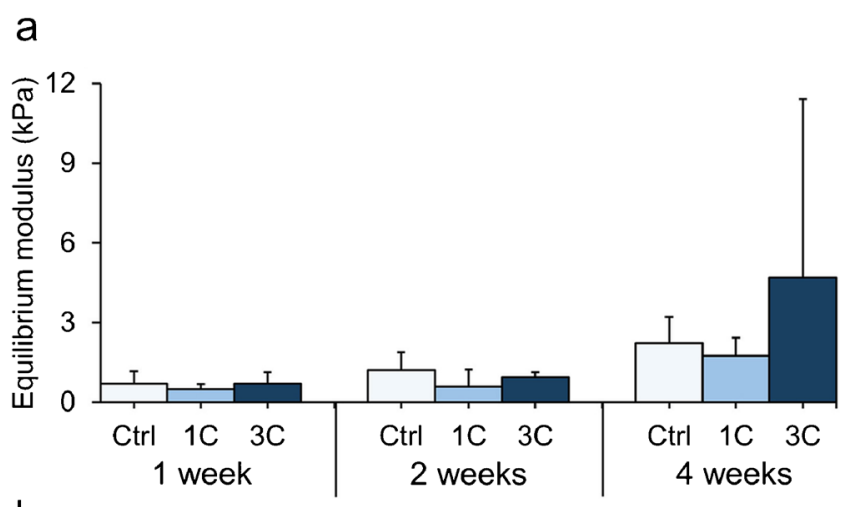

b

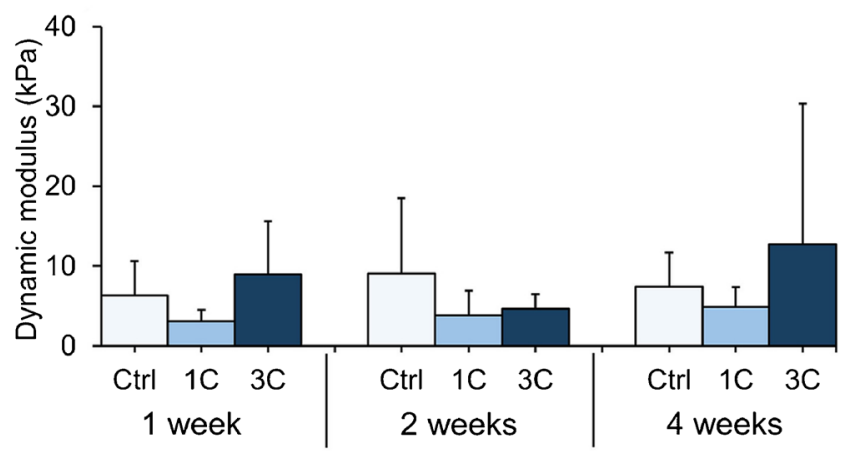

C

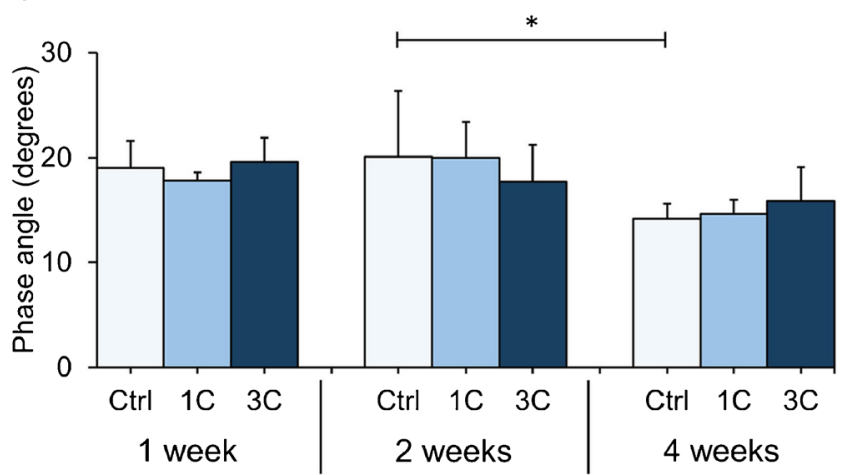

Fig. 3 Equilibrium modulus (a), dynamic modulus (b) and phase angle (c) of the samples. Ctrl, non-centrifuged control; 1C, one centrifugation per day; $3 \mathrm{C}$, three centrifugations per day. Statistically significant differences $(p<0.05)$ are marked with an asterisk (mean $+\mathrm{SD}, n \geq 3)$

type cartilage before moving onto the problem of tissue integration. It is relatively easy to produce a three- dimensional construct out of chondrocytes but deciphering ways to improve the structure of the ECM and the orientational assembly of its components is more complicated. Mechanical stimulation by hydrostatic pressure or direct mechanical strain of cartilage constructs have been shown to improve the biomechanical properties of articular cartilage constructs (Akizuki et al. 1986; Eleswarapu et al. 2011), which are attributed to increase in GAG, PG and type II collagen content (Elder and Athanasiou 2008; Hung et al. 2004; Ikenoue et al. 2003; Shelton et al. 2003; Smith et al. 1996). To our knowledge, our study is the first to report the effects of long-term centrifugation regimen on the ECM production and biomechanics of cartilage constructs.

Under macroscopic inspection, the centrifuged constructs appeared similar to other constructs that have been subjected to mechanical stress with a flatter shape and a more even surface when compared with free swelling counterparts (Hu and Athanasiou 2006; Hung et al. 2004). After 1 month of culture, the manufactured neocartilage tissues displayed similar morphological properties as neonatal cartilage (Hunziker et al. 2007), i.e., the chondrocytes did not appear to have a distinct orientation in deeper sections of the neotissue. However, the chondrocytes on the surface were flattened. The more solid-feeling structure of the centrifuged tissues would also support the initial hypothesis that centrifugation could possibly improve tissue assembly. The rather uniform distribution of PGs in histological sections was probably due to a relatively short time of cultivation (Hu and Athanasiou 2006; Hung et al. 2004). However, the partially visible zonal distribution in some of the sections, which was not visible in the control samples, is a promising finding. On the other hand, the almost complete lack of stained PGs in some of the centrifuged constructs may indicate a local necrosis. The higher concentration of collagen in the superficial layer of the control and once centrifuged constructs, detected by the FTIR mapping, again points to the zonality of the tissue, which can be found in native cartilage.

The nature of the collagen type in the superficial layer cannot be confirmed, since the amide I band of FTIR mapping
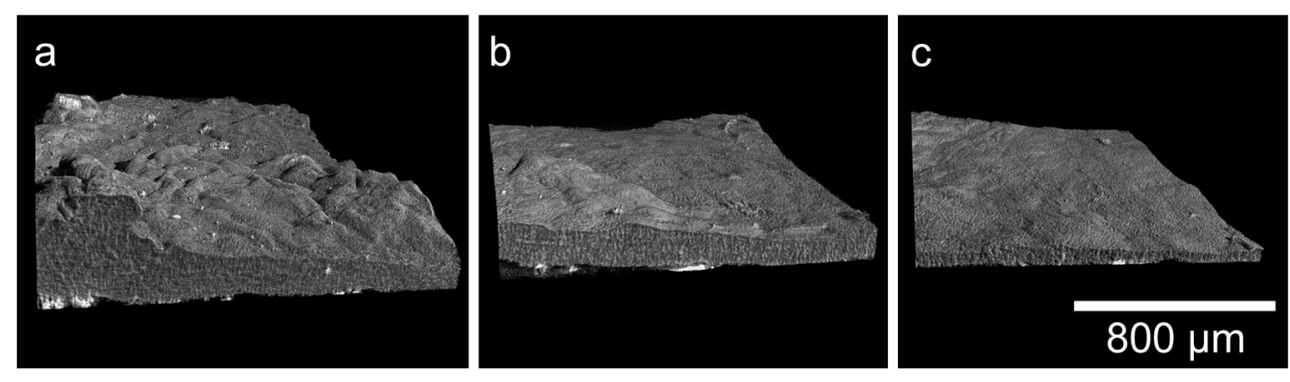

Fig. 4 The centre of the tissue constructs is on the left side in every microCT representation, which shows how the control samples tended to be thicker in the middle than on the edges (a). After 4 weeks of culture, the flattening and smoothing effect of centrifugation is clearly visible in the once centrifuged $(\mathbf{b})$ and three times centrifuged (c) tissues 


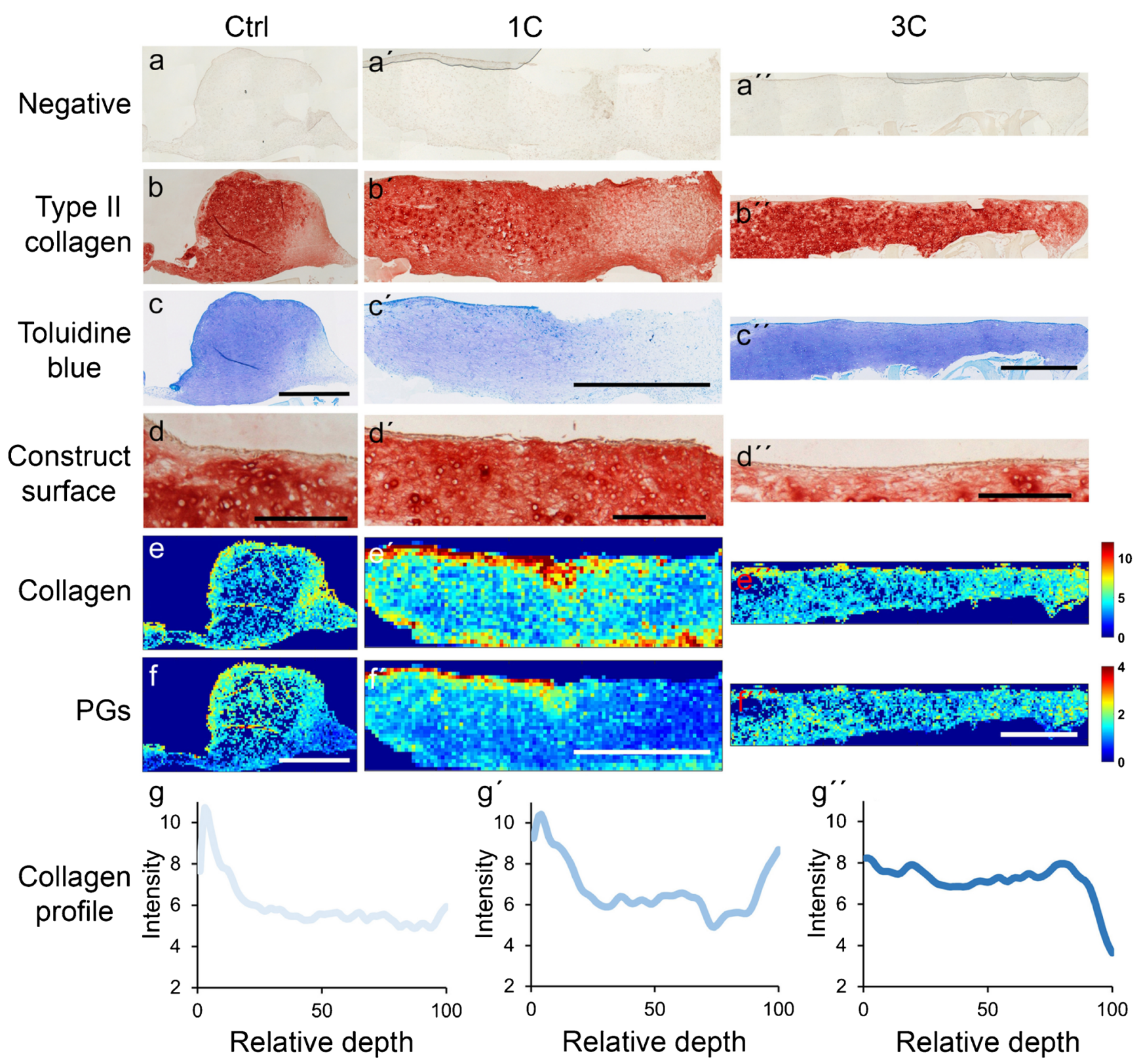

Fig. 5 Negative stains $\left(a-a^{\prime \prime}\right)$, type II collagen $\left(b-b^{\prime \prime}\right)$, toluidine blue (showing as GAG content) (c-c' $\mathrm{c}^{\prime \prime}$ ) stainings after 4 weeks of culture and a magnified picture of the surface show cell morphology on the surface of the tissue and beneath it $\left(\mathrm{d}-\mathrm{d}^{\prime \prime}\right)$. FTIRi maps of amide I (estimate of collagen) (e-e' $\mathrm{e}^{\prime \prime}$ ) and carbohydrate (estimate of GAG) content $\left(\mathrm{f}-\mathrm{f}^{\prime \prime}\right)$. Average depthwise distribution of collagen content

calculated from the FTIRi maps; the relative depth is the distance percentage from the top to the bottom of the section $\left(\mathrm{g}-\mathrm{g}^{\prime \prime}\right)$. Ctrl, noncentrifuged control; $1 \mathrm{C}$, one centrifugation per day; $3 \mathrm{C}$, three centrifugations per day. Scale bar is $1 \mathrm{~mm}$ in all other depictions except for the construct surface, where it is $200 \mu \mathrm{m}$

does not discriminate between the collagen subtypes. Since the FTIR map is scaled to relative intensity, it is possible that the equal distribution of type II collagen is downplayed by a high concentration of type I collagen near the edges. It is also possible that the apparently higher concentrations of PGs, indicated by the FTIR mapping of the carbohydrate band, could also indicate an artefact resulting from tissue shrinking. As the FTIR mapping did not reach the bottom of all the imaged constructs, we cannot make any conclusions on the collagen distribution in the deeper layers.

Neither of the centrifugation regimes appeared to increase the PG production, as indicated by the similar aggrecan expressions and PG quantity between the groups. Nevertheless, they did not have a deleterious effect either and the gel electrophoretic separation of PGs showed them to be comparable in size to what is found in native cartilage. Procollagen $\alpha_{1}$ (II) expression levels did not significantly differ among the tissue constructs, while the remarkably increased expression of procollagen $\alpha_{2}$ (I) was an unexpected finding, as it implies the production of 
Fig. 6 Hydroxyproline (a) and GAG (b) contents were measured and normalised to tissue wet weight (mean $+\mathrm{SD}, n \geq 3$ ).

Extracted PGs were separated by agarose gel electrophoresis (c) to estimate their relative sizes and a densitometric analysis was performed to confirm that the sizes were comparable between the constructs and native cartilage (d). Ctrl, non-centrifuged control; $1 \mathrm{C}$, one centrifugation per day; $3 \mathrm{C}$, three centrifugations per day; Native, native bovine cartilage; CS, chondroitin sulphate. Statistically significant differences $(p<0.05)$ are marked with an asterisk a

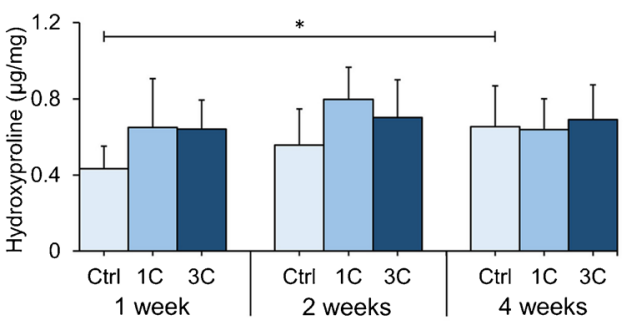

C

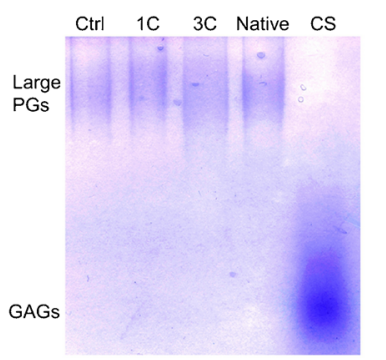

b
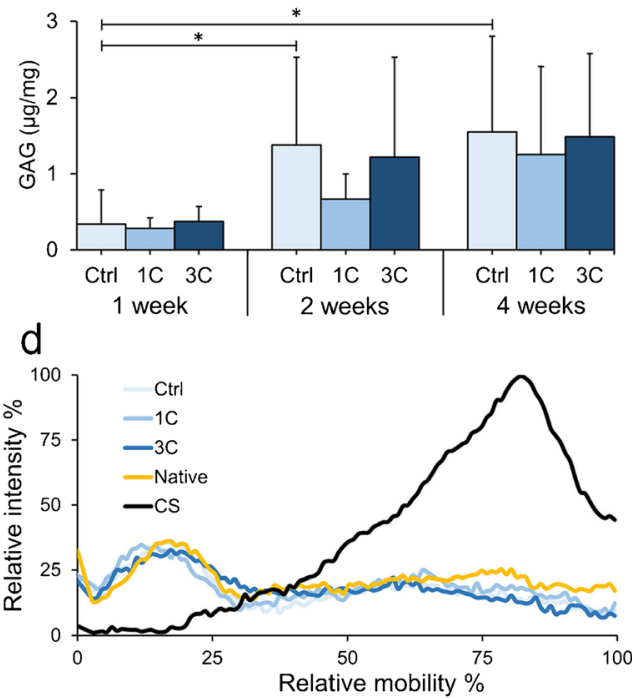

fibrocartilage rather than articular cartilage. Collagen concentration in the constructs was also low, being two orders of magnitude lower than in native bovine cartilage (Williamson et al. 2003) but it was to be expected after the relatively short development time. The collagen quantity in the non-centrifuged controls seemed to be slightly lower than in the centrifuged tissues after 1 week of culture, which might suggest that centrifugation increases collagen production early in the culture but the differences disappeared later.

Our hypothesis was that the additional mechanical force generated by the centrifugal force and the resulting hydrostatic pressure would improve the biomechanical properties of manufactured constructs. However, the only significant difference was observed in the phase angle (representing viscous properties of the tissue) in the controls between 2- and 4-week cultivations. The phase angle of approximately $15^{\circ}$ was similar to that found in normal cartilage at the same frequency (Park et al. 2004). An increase, although non-significant, in the equilibrium modulus would be logical, indicating that the tissues became stiffer with time, which correlates with the observed increase in GAG content (Kempson et al. 1970). The measured moduli were quite low when compared to similar studies (Elder and Athanasiou 2008; Heyland et al. 2006; Hung et al. 2004), which might also be affected by the different loading geometry, protocol and freezing of the samples.

\section{Conclusions}

Micro-CT in particular showed that both of the centrifugation regimes led to more uniform tissue constructs, which had some properties of native cartilage and could be used in the early stages of tissue culture to help shape the neotissue, especially seeing how accessible and cost-effective the method is. However, the formed tissues still only remotely reached the native level of the articular cartilage properties. Therefore, there is a need to improve the culture conditions to help maintain the chondrocyte phenotype.

Acknowledgements We are grateful to Joonas Oinas, Aapo Ristaniemi and Tarja Huhta for technical assistance.

Role of funding source This study was supported by Umeå University, Reumatikerfonden, Insamlingsstiftelsen för medicinsk forskning at Umeå University and European Research Council under the European Union's Seventh Framework Programme (FP/2007-2013)/ERC Grant Agreement No. 336267.

\section{Compliance with ethical standards}

Conflict of interest The authors declare that they have no conflict of interest.

Open Access This article is distributed under the terms of the Creative Commons Attribution 4.0 International License (http:// creativecommons.org/licenses/by/4.0/), which permits unrestricted use, distribution, and reproduction in any medium, provided you give appropriate credit to the original author(s) and the source, provide a link to the Creative Commons license, and indicate if changes were made.

\section{References}

Akizuki S, Mow VC, Muller F, Pita JC, Howell DS, Manicourt DH (1986) Tensile properties of human knee joint cartilage: I. Influence of ionic conditions, weight bearing, and fibrillation on the tensile modulus. J Orthop Res 4:379-392

Anderson DE, Johnstone B (2017) Dynamic mechanical compression of chondrocytes for tissue engineering: a critical review. Front Bioeng Biotechnol 5:76 
Ateshian GA, Ellis BJ, Weiss JA (2007) Equivalence between short-time biphasic and incompressible elastic material responses. J Biomech Eng-Trans ASME 129:405-412

Bosnakovski D, Mizuno M, Kim G, Takagi S, Okumura M, Fujinaga T (2006) Chondrogenic differentiation of bovine bone marrow mesenchymal stem cells (MSCs) in different hydrogels: influence of collagen type II extracellular matrix on MSC chondrogenesis. Biotechnol Bioeng 93:1152-1163

Brown S, Worsfold M, Sharp C (2001) Microplate assay for the measurement of hydroxyproline in acid-hydrolyzed tissue samples. Biotechniques 30:38-40, 42

Camacho NP, West P, Torzilli PA, Mendelsohn R (2001) FTIR microscopic imaging of collagen and proteoglycan in bovine cartilage. Biopolymers 62:1-8

Cheleschi S, De Palma A, Pecorelli A, Pascarelli NA, Valacchi G, Belmonte G, Carta S, Galeazzi M, Fioravanti A (2017) Hydrostatic pressure regulates microRNA expression levels in osteoarthritic chondrocyte cultures via the Wnt/beta-catenin pathway. Int J Mol Sci 18:133

Chiquet M, Renedo AS, Huber F, Flück M (2003) How do fibroblasts translate mechanical signals into changes in extracellular matrix production? Matrix Biol 22:73-80

De Palma A, Cheleschi S, Pascarelli NA, Giannotti S, Galeazzi M, Fioravanti A (2018) Hydrostatic pressure as epigenetic modulator in chondrocyte cultures: a study on miRNA-155, miRNA-181a and miRNA-223 expression levels. J Biomech 66:165-169

Donaldson L, Vuocolo T, Gray C, Strandberg Y, Reverter A, McWilliam S, Wang Y, Byrne K, Tellam R (2005) Construction and validation of a bovine innate immune microarray. BMC Genomics 6:135

DuRaine GD, Brown WE, Hu JC, Athanasiou KA (2015) Emergence of scaffold-free approaches for tissue engineering musculoskeletal cartilages. Ann Biomed Eng 43:543-554

Elder BD, Athanasiou KA (2008) Synergistic and additive effects of hydrostatic pressure and growth factors on tissue formation. PLoS One 3:e2341

Eleswarapu SV, Responte DJ, Athanasiou KA (2011) Tensile properties, collagen content, and crosslinks in connective tissues of the immature knee joint. PLoS One 6:e26178

Farndale RW, Buttle DJ, Barrett AJ (1986) Improved quantitation and discrimination of sulphated glycosaminoglycans by use of dimethylmethylene blue. Biochim Biophys Acta 883:173-177

Galois L, Hutasse S, Cortial D, Rousseau CF, Grossin L, Ronziere MC, Herbage D, Freyria AM (2006) Bovine chondrocyte behaviour in three-dimensional type I collagen gel in terms of gel contraction, proliferation and gene expression. Biomaterials 27:79-90

Harris JD, Siston RA, Pan X, Flanigan DC (2010) Autologous chondrocyte implantation: a systematic review. J Bone Joint Surg Am 92: 2220-2233

Hayes WC, Keer LM, Herrmann G, Mockros LF (1972) A mathematical analysis for indentation tests of articular cartilage. J Biomech 5:541551

Heyland J, Wiegandt K, Goepfert C, Nagel-Heyer S, Ilinich E, Schumacher U, Portner R (2006) Redifferentiation of chondrocytes and cartilage formation under intermittent hydrostatic pressure. Biotechnol Lett 28:1641-1648

Holmdahl R, Rubin K, Klareskog L, Larsson E, Wigzell H (1986) Characterization of the antibody-response in mice with type-II collagen-induced arthritis, using monoclonal anti-type II collagen antibodies. Arthritis Rheum 29:400-410

Hu JC, Athanasiou KA (2006) The effects of intermittent hydrostatic pressure on self-assembled articular cartilage constructs. Tissue Eng 12:1337-1344

Hung CT, Mauck RL, Wang CC, Lima EG, Ateshian GA (2004) A paradigm for functional tissue engineering of articular cartilage via applied physiologic deformational loading. Ann Biomed Eng 32: $35-49$
Hunziker EB, Kapfinger E, Geiss J (2007) The structural architecture of adult mammalian articular cartilage evolves by a synchronized process of tissue resorption and neoformation during postnatal development. Osteoarthr Cartil 15:403-413

Ikenoue T, Trindade MC, Lee MS, Lin EY, Schurman DJ, Goodman SB, Smith RL (2003) Mechanoregulation of human articular chondrocyte aggrecan and type II collagen expression by intermittent hydrostatic pressure in vitro. J Orthop Res 21:110-116

Inoue $\mathrm{H}$, Hiasa K, Samma Y, Nakamura O, Sakuda M, Iwamoto M, Suzuki F, Kato Y (1990) Stimulation of proteoglycan and DNA syntheses in chondrocytes by centrifugation. J Dent Res 69:1560 1563

Kempson G, Muir H, Swanson S, Freeman M (1970) Correlations between stiffness and the chemical constituents of cartilage on the human femoral head. Biochim Biophys Acta 215:70-77

Kim J, Montagne K, Nemoto H, Ushida T, Furukawa KS (2017) Hypergravity down-regulates c-fos gene expression via ROCK/ Rho-GTP and the PI3K signaling pathway in murine ATDC5 chondroprogenitor cells. PLoS One 12:e0185394

Korhonen RK, Laasanen MS, Töyräs J, Rieppo J, Hirvonen J, Helminen HJ, Jurvelin JS (2002) Comparison of the equilibrium response of articular cartilage in unconfined compression, confined compression and indentation. J Biomech 35:903-909

Lynch TS, Patel RM, Benedick A, Amin NH, Jones MH, Miniaci A (2015) Systematic review of autogenous osteochondral transplant outcomes. Arthroscopy 31:746-754

Mäkelä JT, Rezaeian ZS, Mikkonen S, Madden R, Han SK, Jurvelin JS, Herzog W, Korhonen RK (2014) Site-dependent changes in structure and function of lapine articular cartilage 4 weeks after anterior cruciate ligament transection. Osteoarthr Cartil 22:869-878

Meinert C, Schrobback K, Hutmacher DW, Klein TJ (2017a) A novel bioreactor system for biaxial mechanical loading enhances the properties of tissue-engineered human cartilage. Sci Rep 7:1699

Meinert C, Schrobback K, Levett PA, Lutton C, Sah RL, Klein TJ (2017b) Tailoring hydrogel surface properties to modulate cellular response to shear loading. Acta Biomater 52:105-117

Mithoefer K, McAdams T, Williams RJ, Kreuz PC, Mandelbaum BR (2009) Clinical efficacy of the microfracture technique for articular cartilage repair in the knee: an evidence-based systematic analysis. Am J Sports Med 37:2053-2063

Moutos FT, Freed LE, Guilak F (2007) A biomimetic three-dimensional woven composite scaffold for functional tissue engineering of cartilage. Nat Mater 6:162-167

Mow VC, Kuei SC, Lai WM, Armstrong CG (1980) Biphasic creep and stress relaxation of articular cartilage in compression? Theory and experiments. J Biomech Eng 102:73-84

Natenstedt J, Kok AC, Dankelman J, Tuijthof GJ (2015) What quantitative mechanical loading stimulates in vitro cultivation best? J Exp Orthop 2:15

Neuman RE, Logan MA (1950) The determination of collagen and elastin in tissues. J Biol Chem 186:549-556

Ofek G, Revell CM, Hu JC, Allison DD, Grande-Allen KJ, Athanasiou KA (2008) Matrix development in self-assembly of articular cartilage. PLoS One 3:e2795

Park S, Hung CT, Ateshian GA (2004) Mechanical response of bovine articular cartilage under dynamic unconfined compression loading at physiological stress levels. Osteoarthr Cartil 12:65-73

Parkkinen JJ, Ikonen J, Lammi MJ, Laakkonen J, Tammi M, Helminen HJ (1993) Effects of cyclic hydrostatic pressure on proteoglycan synthesis in cultured chondrocytes and articular cartilage explants. Arch Biochem Biophys 300:458-465

Parkkinen JJ, Lammi MJ, Helminen HJ, Tammi M (1992) Local stimulation of proteoglycan synthesis in articular cartilage explants by dynamic compression in vitro. J Orthop Res 10:610-620

Pascarelli NA, Collodel G, Moretti E, Cheleschi S, Fioravanti A (2015) Changes in ultrastructure and cytoskeletal aspects of human normal 
and osteoarthritic chondrocytes exposed to interleukin-1beta and cyclical hydrostatic pressure. Int J Mol Sci 16:26019-26034

Peterson L, Vasiliadis HS, Brittberg M, Lindahl A (2010) Autologous chondrocyte implantation: a long-term follow-up. Am J Sports Med 38:1117-1124

Puhakka PH, Te Moller NC, Tanska P, Saarakkala S, Tiitu V, Korhonen RK, Brommer H, Viren T, Jurvelin JS, Töyräs J (2016) Optical coherence tomography enables accurate measurement of equine cartilage thickness for determination of speed of sound. Acta Orthop $87: 418-424$

Qu C, Lindeberg H, Ylärinne JH, Lammi MJ (2012) Five percent oxygen tension is not beneficial for neocartilage formation in scaffold-free cell cultures. Cell Tissue Res 348:109-117

Ramage L, Nuki G, Salter DM (2009) Signalling cascades in mechanotransduction: cell-matrix interactions and mechanical loading. Scand J Med Sci Sports 19:457-469

Rieppo L, Töyräs J, Saarakkala S (2017) Vibrational spectroscopy of articular cartilage. Appl Spectrosc Rev 52:249-266

Sarasa-Renedo A, Chiquet M (2005) Mechanical signals regulating extracellular matrix gene expression in fibroblasts. Scand J Med Sci Sports 15:223-230

Shelton JC, Bader DL, Lee DA (2003) Mechanical conditioning influences the metabolic response of cell-seeded constructs. Cells Tissues Organs 175:140-150

Smith RL, Rusk SF, Ellison BE, Wessells P, Tsuchiya K, Carter DR, Caler WE, Sandell LJ, Schurman DJ (1996) In vitro stimulation of articular chondrocyte mRNA and extracellular matrix synthesis by hydrostatic pressure. J Orthop Res 14:53-60
Szafranski JD, Grodzinsky AJ, Burger E, Gaschen V, Hung HH, Hunziker EB (2004) Chondrocyte mechanotransduction: effects of compression on deformation of intracellular organelles and relevance to cellular biosynthesis. Osteoarthr Cartil 12:937-946

Tatman PD, Gerull W, Sweeney-Easter S, Davis JI, Gee AO, Kim DH (2015) Multiscale biofabrication of articular cartilage: bioinspired and biomimetic approaches. Tissue Eng Part B Rev 21:543-559

Tchetina E, Mwale F, Poole AR (2003) Distinct phases of coordinated early and late gene expression in growth plate chondrocytes in relationship to cell proliferation, matrix assembly, remodeling, and cell differentiation. J Bone Miner Res 18:844-851

Trzeciak T, Richter M, Suchorska W, Augustyniak E, Lach M, Kaczmarek M, Kaczmarczyk J (2016) Application of cell and biomaterial-based tissue engineering methods in the treatment of cartilage, menisci and ligament injuries. Int Orthop 40:615-624

Wang S, Bao Y, Guan Y, Zhang C, Liu H, Yang X, Gao L, Guo T, Chen Q (2018) Strain distribution of repaired articular cartilage defects by tissue engineering under compression loading. J Orthop Surg Res 13:19

Williamson AK, Chen AC, Masuda K, Thonar EJ, Sah RL (2003) Tensile mechanical properties of bovine articular cartilage: variations with growth and relationships to collagen network components. J Orthop Res 21:872-880

Yang J, Zhang YS, Yue K, Khademhosseini A (2017) Cell-laden hydrogels for osteochondral and cartilage tissue engineering. Acta Biomater 57:1-25

Ylärinne JH, Qu C, Lammi MJ (2014) Hypertonic conditions enhance cartilage formation in scaffold-free primary chondrocyte cultures. Cell Tissue Res 358:541-550 